\title{
Study Abroad Reentry: Behavior, Affect, and Cultural Distance
}

Kelsey M. Gray

Western Oregon University

Victor Savicki

Western Oregon University

Reentry has become a more focused aspect of study abroad in recent years as the field has moved away from a laissez-faire approach and toward an emphasis on intervention and support of study abroad students in their efforts to make sense of their experiences (Vande Berg, Paige \& Lou, 2012). Although not a new concept (Brathurst \& La Brack, 2012), reentry in its more recent incarnation can be seen as an opportunity for students to ratify and reconstrue their encounters with a foreign culture in a way that enhances a sense of self in an intercultural world (Selby, 2008). Despite its history and current popularity, many concepts and ideas about reentry rely on anecdotal, non-research based theorizing. The current study attempts to quantify two important aspects of reentry (behavioral readaptation and emotional response) in the context of measured factors that might impact the intensity of reentry challenges.

\section{Reentry and the W-curve}

Westwood, Lawrence, and Paul (1986) define reentry as:

the continuum of experience and behaviors which are encountered when an individual returns to a place of origin after having been immersed in another context for a period of time sufficient to cause some degree of mental and emotional adjustment prior to optimal functioning in the 'new' environment (p. 223).

This definition specifies some level of acculturation in the host culture, both behavioral adaptation and psychological adjustment, to set the stage for re-adaptation and re-adjustment upon returning home. Without at least a modicum of acculturation to the host environment, students reentering their home environment are not faced with reentry issues. Merely skipping along the surface of another culture, for example as a tourist, does not provoke reentry issues. Immersion is what sets study abroad apart from other forms of travel and contributes to the complexity of reentry.

U-curve. Since reentry depends on some degree of acculturation to the study abroad culture, we will first explore a popular model of intercultural adjustment: the U-curve. This model focuses on phases of adjustment beginning with entry to a culture of sojourn. Lysgaard, one of the psychologists who first described the U-curve, explains:

Adjustment as a process over time seems to follow a U-shaped curve: adjustment is felt to be easy and successful to begin with; then follows a "crisis" in which one feels less welladjusted, somewhat lonely and unhappy; finally one begins to feel better adjusted again, becoming more integrated into the foreign community (Lysgaard, 1955, p. 50).

The stages of the U-curve are referred to as honeymoon, culture shock, recovery, and adjustment, with passage of time as the crucial variable. Oberg (1960) described a variety 
of negative emotions that individuals experience while sojourning, but also asserted that over time individuals will become accustomed to the culture and reach a point of enjoyment and relative ease.

Although very popular, the U-curve model has validity mostly as a heuristic device to provoke discussion about acculturation, since research data do not support the U-curve (Ward, Okura, Kennedy \& Kojima, 1998). Over several studies, psychological well-being and behavioral adaptation were lowest at the beginning of the sojourn, and got better steadily over time rather than being high to begin with, then dipping, then rising (Ward, Okura, Kennedy \& Kojima, 1998; Savicki, Adams, Wilde, \& Binder, 2008). In addition, the experience of culture shock, identified as being at the bottom of the U-curve, does not inevitably lead to psychological distress. The manner in which encounters with the study abroad culture are interpreted, and reinterpreted may lead students to excitement, challenge and a sense of mastery rather than distress. As Bennett (2008) states "disequilibrium need not lead to dissatisfaction" (p. 17). This is not to deny that some students react to acculturative stress in problematic ways; rather the research indicates that distress is not as inevitable as the U-curve model might imply (Savicki, et al., 2004; Savicki, 2010).

W-curve. The challenges to the validity of the U-curve, suggest similar concerns for its extension to reentry: the W-curve. Martin and Harrell (2004) report that while there is limited quantitative research support for the W-curve, "a review of research literature and training materials reveals a continued strong support for the W-curve theory" (p. 313). The U-curve has been extended into a Wcurve to include reentry, to accommodate for the concept that "those reentering their own culture after an extended period in a foreign culture pass through a second U-curve in readjusting, thus forming a W-curve" (Webb, 1983). The second U includes a honeymoon at home, crisis at home, recovery at home, and adjustment at home (Gullahorn \& Gullahorn, 1963). The key driver of difficulty for returning students, according to the W-curve, is "reverse culture shock" (La Brack, 2003). As with the U-curve challenges, the concern is not that some students experience psychological distress and difficulties in readaptation, but rather that the W-curve timing does not necessarily fit the data, and that an implied inevitability of distress and difficulty discounts returning students' resilience in the face of an array of stressors that face them (Bonanno, 2004).

\section{Reentry intensity factors}

Rather than focusing on a time-linked, phase model of reentry adjustment, or a one-dimensional reverse culture shock driver of reacculturation stress, it might be more useful to determine what factors both in the individual and in the situation might intensify the perception of stress upon reentry. Paige (1993) offers a set of nine such intensity factors: cultural difference, ethnocentrism, language, cultural immersion, cultural isolation, prior intercultural experience, expectations, visibility and invisibility, status, and power and control. Although these factors were described as intensifying the study abroad experience, La Brack (2003) proposes that they also apply to reentry. For the purposes of the current research, we will deal with five of the nine factors; individual differences such as ethnocentrism and expectations fall beyond the scope of the current study.

The overarching assumption in using Paige's intensity factors in the reentry setting is that deeper levels of immersion and understanding of a study abroad culture sets the stage for more difficult reentry. Reentry shock would be greater both because leaving a satisfying and exciting experience 
would be wrenching, and because the contrast between home and host cultures would be amplified by a more complete plunge into the host culture. Thus, cultural difference would make reentry more difficult since the contrast between home and host cultures would be heightened. Duration of study abroad might be an indicator of immersion because students would have more time to adapt to the host culture. Age might be a proxy for more intercultural experience, or at least for more maturation. Satisfaction or reported positiveness of the study abroad experience might indicate greater immersion. Fluency in the language of the study abroad culture might also foster a deeper immersion in the host culture. Finally, cultural isolation upon reentry might be operationalized as the lack of ease with which students could contact others who had shared the study abroad experience, once all had returned home.

The current study aims to clarify the connection between behavioral adaptation and psychological adjustment during reentry, as well as delineate factors that may intensify difficulties in reentry. We believe that reentry issues emerge from the synergy of interacting variables. Untangling the complexity of reentry will be necessary to inform effective reentry interventions with returning study abroad students.

\section{Hypotheses and analyses.}

Hypothesis 1. Higher levels of reported behavioral adaptation difficulties during reentry to the U.S. will be related to psychological adjustment indicators of higher negative affect and lower positive affect.

Hypothesis 2. Both behavioral adaptation and psychological adjustment will be related to intensity factors of cultural distance, length of study abroad, age/maturation, positiveness of the study abroad experience, fluency in the host culture language, and geographical closeness of fellow study abroad students upon reentry.

Beyond the specific hypothesis, exploratory analyses were focused on describing what types of reentry difficulties were most problematic for reentering study abroad students, and what types of affect were reported during reentry. Finally, an exploratory analysis focused on the impact of cultural distance on study abroad reentry. Exploratory analyses in this study aim to advance knowledge about reentry by extending the data-driven, research-based findings about this phenomenon.

\section{Methods}

\section{Participants}

Participants were 81 U. S. university, study abroad students who had returned home, ages 18-26; 68 female and 13 male. Study abroad sites included ten countries in Europe, nine in Asia, Australia, New Zealand, seven in Central and South America, and five in Africa. The median length of sojourn was 16 weeks. The median length of time passed since returning to the United States was 32 weeks.

\section{Materials}

A self-report, research survey was constructed asking for demographic and intensity factor information as well as responses to two questionnaires adapted for study abroad reentry. 
Demographic and intensity information. In addition to age, gender, and class standing, participants were asked to indicate the country in which they studied abroad, the duration of their study, the duration of their return to the U.S., degree of fluency in the study abroad country language, the degree to which they studied abroad with peers who were geographically nearby upon reentry, and their evaluation of the overall positiveness of their study abroad experience. Positiveness was rated on a 100 point scale in response to the following question "Using the following scale, please choose a number from 1 to 100 to rate your overall study abroad experience" with $1=$ Extremely negative, 50 $=$ Neutral, and $100=$ Extremely positive. Finally, a Cultural Distance index was calculated using Kogut and Singh's (1988) formula which averaged normalized differences between the U.S. and specific countries in which students studied abroad. These differences were based on research by Hofstede's (2001) cultural work value dimensions of Individualism-Collectivism, Uncertainty Avoidance, Power Distance, and Masculinity vs Femininity. Each participant had a Cultural Distance score specific to his or her study abroad country.

Reentry Adaptation Scale. An 18 item Reentry Adaptation Scale was modeled after the Sociocultural Adaptation Scale (SCAS) (Ward \& Kennedy, 1999). The SCAS has usually been used to measure reported difficulties in performing adaptive behaviors during acculturation to a country of sojourn. Because this study addresses reentry, the tool needed to be refocused to assess the level of difficulty that participants reported for specific behaviors related to reentry, e.g. "Readapting to the pace of life at home," "Changing behavior to suit social norms back home." On the resulting scale items, responses varied from $1=$ Very easy, to $5=$ Very difficult. Cronbach's alpha for this scale was .865 .

Reentry Positive and Negative Affect Scale (RPANAS). The Positive and Negative Affect Scale (PANAS) (Watson, Clark, \& Tellegen, 1988), designed to measure mood states for specific time periods, was modified to better reflect affect or psychological well-being that might be present during study abroad reentry. Items such as "jittery" and "strong" were replaced by items such as "disconnected" and "accepted." Substitution of positively and negatively toned items is consistent with the PANAS scale rationale in that the overall positive or negative valence of an item was more important to the scale developers than specific, discrete emotions (Watson, Clark, \& Tellegen, 1988). A principle components factor analysis using a varimax rotation of the 20 item RPANAS confirmed the two factor solution (positive affect $28.76 \%$ of variance, and negative affect $12.45 \%$ of variance). Participants responded to the following question "Thinking back on your feelings since you came back from your study abroad, please indicate to what extent you have felt this way during your readjustment to living in the U.S." on a five point scale with 1 = "Very slightly or not at all," 5 = "Extremely." The Positive Affect scale had a Cronbach's Alpha of .791, and the Negative Affect scale had a Cronbach's Alpha of .828.

\section{Procedures}

The survey questionnaire was delivered to returning study abroad students in one of two ways. First, a paper and pencil version was delivered during meetings of reentry students who were participating in a reentry program (e.g. class, workshop, informational meeting). These questionnaires were introduced and collected by the primary investigator, or the individual responsible for conducting the program. Second, an identical on-line survey was available to returning students from geographically distant colleges and universities. Responses from both data collection formats were 
combined. The sample was a convenience sample.

\section{Results}

After discussing the outcomes for our specific research hypotheses, we will describe further exploratory analyses.

\section{Hypothesis 1: Adaptation and adjustment}

Hypothesis 1 stated that higher difficulties in reentry behavioral adaptation would be related to psychological adjustment in the form of higher negative affect and lower positive affect. As table 1 reveals, this hypothesis is supported since the correlation between the Reentry Adaptation Scale and the Negative Affect scale was $.598(\not<.01)$ and the correlation between the Reentry Adaptation Scale and the Positive Affect scale was -.462 $(p<.01)$. To give some perspective, in relation to the normative sample used by the PANAS developers (Watson, Clark \& Tellegen, 1988), the current sample's Positive Affect is relatively the same, and their Negative Affect is slightly elevated. As a caution, the correlations supporting this hypothesis do not indicate causality. That is, it is yet to be determined if behavioral adaptation difficulties cause the observed adjustment affect, or vice versa. Nevertheless, the strong connection between behavioral adaptation and psychological adjustment in the reentry process echoes the connection between these two levels of acculturation in the study abroad setting (Ward, Okura, Kennedy \& Kojima, 1998; Ward, Bochner, \& Furnham, 2001).

Table 1. Mean, SD's and correlations for intensity factors with adaptation and adjustment.

\begin{tabular}{llllll}
\hline & & & Reentry Adaptation & Positive \\
& Mean & SD & Scale & Affect & Negative Affect \\
\hline Reentry Adaptation Scale & 3.182 & 0.675 & & & \\
Positive Affect & 3.174 & 0.691 & $-.426^{* *}$ & $-.406^{* *}$ & $.208+$ \\
Negative Affect & 2.301 & 0.683 & $.598^{* *}$ & -.063 & .062 \\
Cultural Distance & 12.386 & 7.402 & .186 & -.145 & .067 \\
Study Abroad Positiveness & 88.040 & 14.729 & $.374^{* *}$ & .067 & -.071 \\
Age & 21.230 & 1.335 & -.037 & .056 &. $.218^{*}$ \\
Language fluency & 2.300 & 1.699 & .005 & -.109 & $.287^{*}$
\end{tabular}

$+p<.10, * p<.05, * * p<.01$

\section{Hypothesis 2. Intensifying factors}

Hypothesis 2 stated that various intensifying factors would relate to reentry behavioral adaptation and reentry psychological adjustment (cf. Table 1 for correlation coefficients). First, two of the intensifying factors had no significant relationship with reentry adaptation and adjustment in this sample: language fluency, age/maturity. Positive student evaluations of their study abroad experience 
was strongly correlated with higher reentry adaptation difficulties, but not with adjustment. This finding is consistent with the notion that deeper immersion into the host culture environment may yield more adaptation difficulties upon reentry. Study abroad length was inversely related to positive affect, but not related to negative affect. Both cultural distance and the availability of other study abroad students upon reentry were positively related to negative affect, but not related to positive affect. Cultural distance and study abroad length are related to psychological adjustment as hypothesized. The picture drawn by the correlations in Table 1 gives some support for the impact of intensifying factors, yet there seems to be a differentiation in terms of whether they relate to adaptation or adjustment. No single intensifying factor relates to both. The availability of other study abroad peers upon reentry actually showed a significant correlation in the opposite direction than predicted. These students may have gotten together to commiserate with one another, and in doing so amplified the sadness and loss they felt after leaving their study abroad setting. Clearly more research needs to be done to tease out the effects of these various intensifying factors. They seem to make a difference, but the scope and depth of that impact is, as yet, unclear.

\section{Exploratory analysis: Reentry difficulties}

In order to better understand what adaptive tasks might best describe the reentry difficulties encountered by participants in this study, the total sample was separated into two groups split at the median of the Reentry Adaptation Scale: High Difficulty group $(n=41)$ and Low Difficulty group $(n=40)$. Table 2 is sorted so that differences between the groups are in descending order. The first nine items in the table show a one point or more difference between the groups; these differences are significant at the .01 level or better. Examination of these items shows two intertwined themes: readapting to the U.S. culture (e.g. Accepting American values, Changing behavior to suit social norms back home), and reestablishing relationships and activities back home (Reestablishing relationships with home friends and family, Reentering school life in the U.S.). Significant though less intense differences revolved around loss of features of the study abroad experience (e.g. Finding the level of intensity at home that you experienced abroad, Leaving the values of the host country). The groups did not differ on the perceived difficulty of the relatively high scoring item "Maintaining relationships from abroad."

The highest difficulty items for the High Difficulty group (rated 4 or more on a 5 point scale) were: "Readapting to the pace of life at home," "Accepting your study abroad experience had ended," "Finding a level of intensity at home that you experienced abroad," " Leaving the pace of life in the study abroad country," "Leaving host country friends." These items suggest a theme of loss for the High Difficulty group that might fit well with the lower positive and higher negative affect results reported earlier. 
Table 2. Differences between High and Low Difficulty groups on Reentry Adaptation Scale items

\begin{tabular}{|c|c|c|c|c|c|}
\hline \multirow[b]{2}{*}{ Reentry Adaptation Scale Items } & \multicolumn{2}{|c|}{ Low Difficulty } & \multicolumn{2}{|c|}{ High Difficulty } & \multirow[b]{2}{*}{$\mathrm{F}$} \\
\hline & Mean & Std. Error & Mean & Std. Error & \\
\hline Readapting to the pace of life at home & 2.375 & 0.151 & 4.122 & 0.149 & $68.019 * *$ \\
\hline $\begin{array}{l}\text { Reestablishing relationships with home } \\
\text { friends and family }\end{array}$ & 1.875 & 0.180 & 3.415 & 0.178 & $37.054 * *$ \\
\hline $\begin{array}{l}\text { Changing behavior to suit social norms } \\
\text { back home }\end{array}$ & 2.000 & 0.159 & 3.366 & 0.157 & $37.528^{* *}$ \\
\hline $\begin{array}{l}\text { Finding someone to listen to your } \\
\text { experience }\end{array}$ & 2.275 & 0.188 & 3.561 & 0.186 & $23.602^{* *}$ \\
\hline $\begin{array}{l}\text { Maintaining personal balance in day-to- } \\
\text { day life back home }\end{array}$ & 2.450 & 0.171 & 3.732 & 0.168 & $28.577^{* *}$ \\
\hline $\begin{array}{l}\text { Accepting your study abroad experience } \\
\text { had ended }\end{array}$ & 2.950 & 0.170 & 4.220 & 0.168 & $28.352^{* *}$ \\
\hline $\begin{array}{l}\text { Sharing study abroad experience with } \\
\text { friends and family }\end{array}$ & 2.575 & 0.191 & 3.780 & 0.188 & $20.248^{* *}$ \\
\hline Accepting American values & 2.575 & 0.172 & 3.756 & 0.170 & $23.906 * *$ \\
\hline Reentering school life in the US & 2.675 & 0.183 & 3.780 & 0.181 & $18.476 * *$ \\
\hline $\begin{array}{l}\text { Finding level of intensity at home that you } \\
\text { experienced abroad }\end{array}$ & 3.175 & 0.148 & 4.171 & 0.147 & $22.792 * *$ \\
\hline $\begin{array}{l}\text { Leaving the pace of life in study abroad } \\
\text { country }\end{array}$ & 3.250 & 0.172 & 4.244 & 0.170 & $16.979 * *$ \\
\hline Interacting at social events & 2.050 & 0.164 & 3.024 & 0.162 & $17.892^{* *}$ \\
\hline Leaving values of host country & 2.650 & 0.182 & 3.610 & 0.180 & $14.051 * *$ \\
\hline $\begin{array}{l}\text { Engaging in hobbies and activities from } \\
\text { home }\end{array}$ & 2.00 & 0.155 & 2.951 & 0.153 & $19.067 * *$ \\
\hline $\begin{array}{l}\text { Maintaining personal growth gained while } \\
\text { abroad }\end{array}$ & 2.450 & 0.197 & 3.220 & 0.195 & $7.705^{*}$ \\
\hline Leaving host country friends & 3.700 & 0.176 & 4.244 & 0.174 & $4.830^{*}$ \\
\hline $\begin{array}{l}\text { Engaging in hobbies and activities from } \\
\text { abroad }\end{array}$ & 3.150 & 0.180 & 3.683 & 0.177 & $4.455^{*}$ \\
\hline Maintaining relationships from abroad & 3.475 & 0.169 & 3.805 & 0.167 & 1.925 \\
\hline
\end{tabular}




\section{Exploratory analysis: Positive and negative affect}

Table 3 shows the differences between High Difficulty and Low Difficulty groups on Positive and Negative Affect. On the overall scores of the RPANAS, High and Low Difficulty groups differed significantly on Positive Affect with the Low Difficulty group higher $(\mathrm{F}=22.266, p<.001)$ and on Negative Affect with the High Difficulty group higher $(F=23.293, p<.001)$. In the Positive Affect section of table 3, the individual scale items of Joyful and Excited indicated an almost one point difference between the groups. The Low Difficulty group found reentry more intensely positive. At a more sedate level of positive affect (Present, Content, Relieved, Accepted) the Low Difficulty group reported such affect at roughly three quarters of a point higher. The item "Accepted" showed elevation for both groups. This emotion seems quite important for all returning students. There were no differences between the groups on the terms "Proud," or "Inspired," for the most part because the High Difficulty group reported higher levels of these emotions. On average, the Low Difficulty group reported substantially higher levels of positive affect than negative affect. This result is consistent with findings from the norm group used to develop the PANAS (Watson, Clark, \& Tellegen, 1988). The High Difficulty group, however, showed relatively equal levels of positive and negative affect, thus indicating a qualitatively different emotional experience of reentry.

For Negative Affect, the feeling of being "Disconnected" was the strongest difference between the Low and High Difficulty groups. High difficulty students did not feel reconnected with their home environment. In addition, the High Difficulty group showed significantly higher irritability, distress, disappointment, and boredom. The High and Low Difficulty groups were not different on "Nervous," "Guilty," or "Ashamed.", as these emotions seemed to be low and even perhaps irrelevant to all returning students. The transition back home was more fraught with negative emotion for the High Difficulty group.

Combining the results for both positive and negative emotions, it seems clear that at the level of psychological adjustment, students who experience a higher level of difficulty with reentry have a more emotionally arduous transition seeking to reconnect to life in the U.S. 
Kelsey M. Gray \& Victor Savicki

Table 3. Differences between High and Low Reentry groups on RPANAS Scale items

\begin{tabular}{|c|c|c|c|c|c|}
\hline & Low Di & & High Di & & \\
\hline Positive Affect & Mean & SD & Mean & SD & $F$ \\
\hline Joyful & 3.625 & 0.838 & 2.683 & 0.960 & $22.093 * * *$ \\
\hline Excited & 3.625 & 0.979 & 2.707 & 1.078 & $16.062 * * *$ \\
\hline Present & 3.500 & 0.877 & 2.732 & 1.073 & $12.415^{* * *}$ \\
\hline Content & 3.375 & 0.979 & 2.610 & 0.997 & $12.144^{* * *}$ \\
\hline Relieved & 2.825 & 1.196 & 2.073 & 1.212 & $7.892 * *$ \\
\hline Accepted & 4.050 & 0.815 & 3.341 & 0.990 & $12.331^{* *}$ \\
\hline Interested & 3.425 & 1.059 & 2.878 & 1.053 & $5.427^{*}$ \\
\hline Proud & 3.550 & 1.260 & 3.146 & 1.315 & 1.989 \\
\hline Inspired & 3.525 & 1.281 & 3.537 & 1.247 & 0.002 \\
\hline Negative Affect & Mean & SD & Mean & SD & $F$ \\
\hline Disconnected & 2.325 & 1.071 & 3.683 & 1.128 & $30.835 * * *$ \\
\hline Irritable & 1.925 & 0.997 & 2.805 & 1.123 & $13.880 * * *$ \\
\hline Distressed & 1.925 & 0.917 & 2.756 & 1.241 & $11.712 * * *$ \\
\hline Disappointed & 2.075 & 1.047 & 2.854 & 1.152 & $10.113^{* *}$ \\
\hline Bored & 2.525 & 1.086 & 3.268 & 1.323 & $7.617 * *$ \\
\hline Confused & 2.250 & 1.149 & 2.927 & 1.421 & $5.539 *$ \\
\hline Distracted & 2.825 & 1.083 & 3.366 & 1.178 & $4.619^{*}$ \\
\hline Unaccepted & 1.300 & 0.516 & 1.805 & 1.030 & $7.716^{*}$ \\
\hline Nervous & 1.675 & 0.829 & 2.098 & 1.091 & 3.840 \\
\hline Guilty & 1.600 & 1.081 & 1.951 & 1.182 & 1.944 \\
\hline Ashamed & 1.275 & 0.784 & 1.317 & 0.789 & 0.058 \\
\hline
\end{tabular}

$* p<.05, * * p<.01, * * * p<.001$ 


\section{Exploratory analysis: Cultural Distance as a moderator}

The significant relationship between Reentry Adaptation Scale and Positiveness of Study Abroad Experience, as well as the marginally significant relationship between Cultural Distance and Negative Affect (see Table 1), sparked the notion that these results might point to a more complex interplay among the variables. In order to investigate this possibility, a moderation analysis was undertaken to determine whether or not Cultural Distance might moderate the relationship between reentry difficulty and positiveness of the study abroad experience. Following the procedures outlined by Baron and Kenney (1986), a multiple regression was conducted to test whether the interaction between the moderator variable (Cultural Distance) and the predictor variable (Positiveness of Study Abroad Experience) was statistically significant when predicting Reentry Adaptation, thus indicating a moderation effect. The first order positive correlation between perceived positiveness and reentry difficulties $(r=.374, p<.001)$ was moderated significantly by cultural distance (interaction beta $=-.320$, $p<.003$ ). In Figure 1, following Aiken and West's (1991) procedures, we plotted three slopes to display visually how Cultural Distance moderated the relationship between positiveness and reentry difficulties. These lines represent Cultural Distance points at the mean and one standard deviation above (High) and below the mean (Low).

The lines plotted in figure 1 indicated that for students in study abroad cultures that were quite distant from the U.S. culture (High), reentry difficulties were high regardless of the positiveness of the study abroad experience, the slope of the line is not significantly different from zero. The difference of the culture trumped the positiveness of the experience. Countries in this sample most culturally distant from the U.S. included Costa Rica (25.6), Ecuador (25.2), South Korea (21.8), Greece (20.8), Uganda (19.4). For students in study abroad cultures that were very close to the U.S. (Low), cultural distance did not have much influence. The positiveness of the experience related most clearly to reentry difficulties with higher positiveness related to lower difficulties in reentry; the slope of the line was statistically significant $(t=4.40, p<.01)$. Countries in the low range of cultural distance in this sample included Australia (0.11), Great Britain (0.40), New Zealand (1.4), South Africa (2.3), Germany (2.7), Italy (3.1). For students in study abroad countries that were in the mid range of distance from the U.S. (Mid), reentry difficulties rose as the positiveness of the study abroad experience increased; the slope of the line was statistically significant $(t=2.00, p<.05)$. The more positive the experience for students in these countries, the more difficult the reentry back into the U.S. culture. Countries in the mid range of distance for this sample included Norway (9.8), Spain (10.4), Thailand (12.1), Senegal (12.2), Peru (12.9), Brazil (13.2), Japan (14.6). 


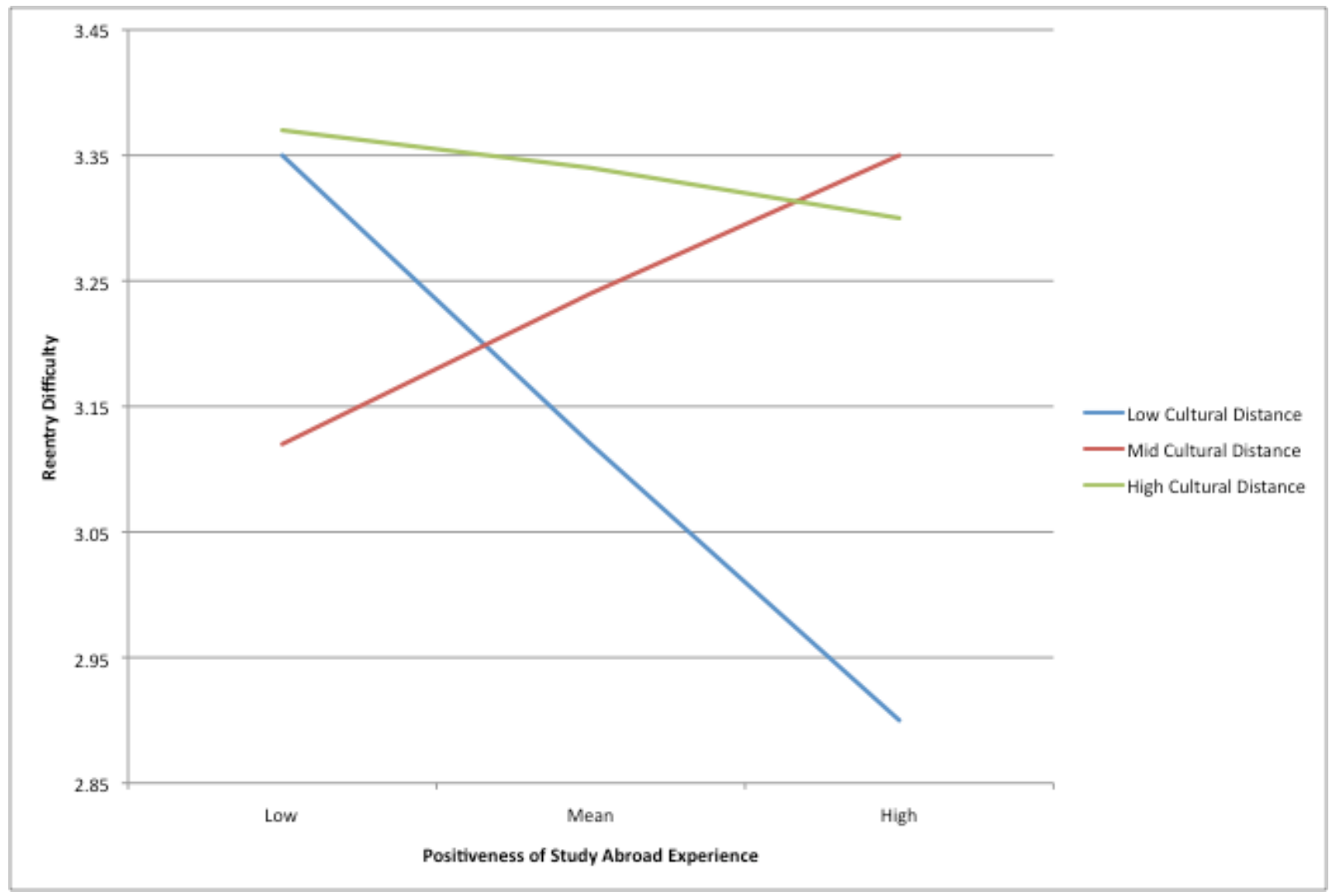

Figure 1. Moderation effect of Cultural Distance on the relationship of Reentry Difficulty and Positiveness of Study Abroad

In summary, Cultural Distance changed the relationship between Positiveness of the Study Abroad Experience and Reentry Difficulties. Sometimes the differentness of the study abroad culture overshadowed students' perceived positiveness of experience, and sometimes cultural distance did not seem to have much impact at all. In the broad, mid-range of the distribution of cultural distance, greater positiveness was related to higher reentry difficulties, which may imply that greater immersion lead to a higher level of difficulty upon reentry. Cultural distance, as an intensifying factor, yields a mixed picture in relation to reentry difficulties.

\section{Discussion}

Several themes emerge from hypotheses testing and exploratory analyses. As an overarching premise we assert that reentry is a complex phenomenon with several important and inextricably intertwined processes. To view reentry as simply a reaction to loss, or as reverse culture shock underestimates the richness of the experience.

\section{Themes}

An initial theme emerging from the current findings is that reverse culture shock, or something like it, influences study abroad reentry. High Difficulty students found readapting to home culture values more onerous than did Low Difficulty students. In addition, the cultural distance moderator effect indicated that cultures more distant from the U.S. had different impacts than did those cultures less distant. Clearly interacting with a different culture can set the stage for difficulties in reentry. 
Future research might focus in the "acculturation strategies" adopted by study abroad students as well as the distance of the culture. Berry (2005) suggests that strategies like Assimilation and Integration emphasize identification with the host culture as a part of adapting to the stresses of acculturation that study abroad students may encounter during their time in the host culture. One might expect that students adopting these strategies would have a different reentry experience than students using the Separation strategy in which students hold themselves apart from the host culture. In addition, Adler (2002) specifies categories of returnees from foreign placements (Resocialized, Proactive, Alienated) based on their orientation toward home and host cultures. It would be informative to determine if higher levels of immersion in and identity with the host cultures lead to more intense reverse culture shock upon reentry, as is suggested by students in mid cultural distance countries who reported higher levels of positiveness of experience.

A second emerging theme is that of loss of the unique study abroad experience as students return home. For some, maybe most, the time abroad is a once in a lifetime experience. Contacts made, friendships forged, skills learned, and awarenesses garnered will not be repeated. The yearning for a possibly idealized experience ever receding into the past can engender a loss arousing predictable separation and grief reactions. Part of the reentry process might focus on how to integrate that distinct window of time in the student's life into a broader sense of identity and values rather than to encapsulate or "shoe-box" it to be remembered fondly, but to be seen as irrelevant to ongoing life (Brathurst \& La Brack, 2012).

A third theme deals with the stressors of reestablishing relationships with people back home, and picking up the threads of life left dangling during study abroad. Clarification concerning stressors such as these might be directed toward the goal of teasing out how much such everyday stressors are also laden with acculturative stress. For example, how much does starting a new semester at the university yield just the usual level of stress, and how much it is amplified because the student's expectation of academic life is now tinged with the values and assumptions gleaned from his or her time in their host culture. Some of the reentry transitions are just transitions that would have occurred even if the student had taken a semester off to work in a McDonalds in Cleveland, and some are more complicated because of the study abroad experience. Not all stress students experience at reentry must be related to their host culture sojourn. Reentry difficulties are probably not all related to the experience of life in another country, but rather just the experience of a new and different way of life for a time.

A fourth theme focuses on the predictable affect and emotion that accompanies study abroad reentry. The literature is rife with concerns over negative emotional consequences of reentry. The W-curve model presumes negative reactions. Surely there are both negative and positive emotions involved in the reentry process. However, to generalize that all returning students experience debilitating affect ignores the experience of the Low Difficulty group whose Negative Affect scores were roughly equivalent to the PANAS norm group, and whose Positive Affect scores were slightly elevated. These students were significantly more joyful and excited than their High Difficulty peers, and even the High Difficulty group was proud and inspired to the same degree as their Low Difficulty peers. A substantial percentage of students show a robust and resilient readaptation to life back in the U.S. Reentry is not necessarily a traumatic event, as described by some writers (Chamove \& Soeterik, 2006). At the same time, some students do struggle. It is our hope that the findings of the 
current study will guide international educators and advisors toward avenues to help those students. As with other major life events, study abroad and reentry seem to be a mix of both positive and negative emotions, and there need not be a focus solely on the agonies or ecstasies of the experience, but rather a holistic approach that can support students and help them understand the full range of reactions to their experience.

\section{Limitations and future research}

A major limitation of the current study is the lack of a cognitive component to the research dataset. Ward (2001) promotes an ABC framework when considering acculturation: Affect, Behavior, Cognition. The current study addresses behavior (Reentry Adaptation Scale) and affect (RPANAS), but omits information on social identity which is the cognitive aspect that Ward identifies. Future research on reentry should include all of the $A B C$ 's.

Methodologically speaking, reentry research would benefit from control groups. In the current study, the Low Difficulty group looked much like the PANAS norm group. It may be that only a small subset of returning students experience stressors above and beyond those experienced by students who stayed at home. Navigating the thickets of higher education may not be made more onerous by the study abroad experience. It may be difficult in its own right.

The Positiveness of Study Abroad Experience scale was a very general, one item measure. Future researchers might construct a more differentiated, multiple item survey in order to discriminate student reactions to different aspect of their experience. The assumption is that different aspects of the experience might have differential impacts on reentry. Likewise, other intensifying factors deserve better measurement.

Although the majority of study abroad students from the U.S. are female (65\%), the current sample exceeds that number $(84 \%)$. More balance is needed in future research.

Finally, future research might follow study abroad students longitudinally over several time periods to track their changes and adjustment as they readapt during reentry. Anecdotal reports indicate changes in the reentry process over time, and possibly an "incubation effect" such that more and deeper reflections on students' study abroad experiences occur as time passes. Tracking both adaptation and adjustment over time could reveal critical periods in the reentry process.

\section{Conclusions}

Reentry is more complex than "reverse culture shock," though it seems to contain that component. Rather than depend on the W-curve as a framework for thinking about reentry, international educators might turn to the notion of intensity factors (Paige, 1993) which seem to offer a more nuanced approach that does not depend on the passage of time, or the presumption of trauma, or solely the impact of cultural confusion. There are hints of how intensity factors impact reentry adaptation and adjustment, but much more research is required to tease out the complex interplay of these factors.

The current study strove to fill some information gaps about the reentry process, and made both expected and unexpected connections. Overall, it elaborated existing knowledge of reentry and added depth and details. It is hoped that we will see data-based, research literature available on study abroad 
reentry continue to grow, and awareness of this topic to increase.

Finally, in terms of practical application for international educators and advisors, the concept of the W-curve is only suggestive of student reentry difficulties. In its historic form, it misses the timing of the most intense student difficulties, it over emphasizes negative emotion, at least for many returning students, and it ignores a variety of sources of stress that reentering students face. A sensitive faculty or advisor receiving a reentering student would do well to peruse the intensity factors of each specific student to develop a more holistic picture of potential issues that each student might face.

\section{References}

Adler, N. J., (2002). International Dimensions of Organizational Behavior (4th ed.). Cincinnati, OH: SouthWestern.

Aiken, L. S. \& West, S. G. (1991). Multiple Regression: Testing and Interpreting Interactions. Newbury Park, CA: Sage Publications.

Baron, R. M., \& Kenny, D. A. (1986). The moderator-mediator variable distinction in social psychological research: Conceptual, strategic, and statistical considerations. Journal of personality and social psychology, 51(6), 1173.

Bennett, J. M. (2008). On becoming a global soul: A path to engagement on study abroad. In V. Savicki, (Ed). Developing Intercultural Competence and Transformation: Theory, Research, and Application in International Education. Sterling, VA: Stylus Publishing.

Berry, J. W. (2005). Acculturation. In W. Friedlmeier, P. Chakkarath, \& B. Schwarz (Eds.) Culture and Human Development (pp. 291-302). New York, NY: Psychology Press.

Bonanno, G. A. (2004). Loss, trauma, and human resilience: Have we underestimated the human capacity to thrive after extremely aversive events? American Psychologist, 59, 20-28.

Brathurst, L, \& La Brack, B. (2012). Intervening prior to and after student experiences abroad. In M. Vande Berg, R. M. Paige, \& K. H. Lou (Eds.). Student Learning Abroad: What our students are learning, what they're not, and what we can do about it., (pp. 261-283). Sterling, VA: Stylus Publishing.

Chamove, A., \& Soeterik, S. (2006). Grief in returning sojourners. Journal of Social Science, 13, 215-220.

Gullahorn, J.T., \& Gullahorn, J.E. (1963). An extension of the U-curve hypothesis. Journal of Social issues, 19(3), 33-47.

Hofstede, G. H. (2001). Culture's Consequences: Comparing Values, Behaviors, Institutions, and Organizations across Nations. Thousand Oaks, CA: Sage Publications.

Kogut, B., \& Singh, H. (1988). The effect of national culture on the choice of entry mode. Journal of international business studies, 411-432.

La Brack, Bruce (2003). What's up with culture? Retrieved from http://www.pacific.edu/culture.

Lysgaard, S. (1955). Adjustment in a foreign society: Norwegian Fulbright grantees visit the United States. Acta Psychologica. 11,189-190.

Martin, J. N., \& Harrell, T. (2004). Intercultural reentry of student and professionals: Theory and practice. In D. Landis, J.M Bennet, \& M. J. Bennett (Eds.). Handbook of Intercultural Training (3rd ed.). Thousand Oaks, CA: SAGE Publications.

Oberg, K (1960). Cultural shock: Adjustment to new cultural environments. Practical Anthropology, 7, 177-182

Paige, R. M. (1993). On the nature of intercultural experiences and intercultural education. In R. M. Paige (Ed.). Education for the intercultural experience. Yarmouth, ME: Intercultural Press

Savicki, V. (2010). Implications of early sociocultural adaptation for study abroad students. Frontiers: The Interdisciplinary Journal of Study Abroad XIX, 205-223. 
Savicki, V., Adams, I., Wilde, A., \& Binder, F. (2008). Intercultural development: Topics and sequences. Frontiers: The Interdisciplinary Journal of Study Abroad, XV, 111-126.

Savicki, V., Downing-Burnette, R., Heller, L., Binder, F., \& Suntinger, W. (2004). Contrasts, changes, and correlates in actual and potential intercultural adjustment. International Journal of Intercultural Relations. 28, 311-329.

Selby, R. (2008). Designing transformation in international education. In V. Savicki (Ed.), Developing intercultural competence and transformation (1 ed., pp. 1-10). Sterling, Virginia: Stylus Publishing.

Vande Berg, M., Paige, R. M., \& Lou, K. H. (Eds.). Student Learning Abroad: What our students are learning, what they're not, and what we can do about it. Sterling, VA: Stylus Publishing.

Ward, C., Bochner, S., \& Furnham, A. (2001). The psychology of culture shock. (2 ed.) Philadelphia, PA: Routledge.

Ward, C. (2001). The A, B, Cs of acculturation. In D. Matsumoto (Ed.), Handbook of Culture and Psychology. (pp. 411-446). NY: Oxford University Press.

Ward, C., \& Kennedy, A. (1999). The measurement of sociocultural adaptation. International Journal of Intercultural Relations, 23(4), 659-677.

Ward, C., Okura, Y., Kennedy, A., \& Kojima, T. (1998). The u-curve on trial: A longitudinal study of psychological and sociocultural adjustment during cross-cultural transition. International Journal of Intercultural Relations, 22(3), 277-291.

Watson, D., Clark, L., \& Tellegen, A. (1988). Development and validation of brief measures of positive and negative affect: the PANAS scales .Journal of Personality and Social Psychology,54(6), 1063-1070.

Webb, M. W. (1983). Cross-cultural awareness: A framework for interaction. Personnel and Guidance Journal, 61(8), 498-500.

Westwood, M. J., Lawrence, W. S., \& Paul, D. (1986). Preparing for re-entry; a program for the sojourning student. International Journal for the Advancement of Counselling, 9, 221-230. 